\title{
PENGARUH TERAPI TAUBAT DAN ISTIGHFAR DALAM MENURUNKAN KECEMASAN MAHASISWA
}

\author{
Dian Nugrahati \\ Qurotul Uyun \\ Sumedi P Nugraha1
}

Program Studi Psikologi Profesi (S2), Universitas Islam Indonesia, Yogyakarta

\begin{abstract}
The aim of this research is to look at the effect of taubat dan istighfar or repentance and seeking forgiveness therapy on anxiety. The subject of this research is psychology students. The research was carried out in the form of quasi-experimental, using pre-test analysis, post-test analysis, and follow-up. Before the treatment, all of the subjects were given the anxiety scale using the Beck Anxiety Inventory (BAI), in which subject with high and moderate anxiety will be used as research subjects. The data were analyzed using the T-test method to measure the significance and effect size on both variables. The results are $r=0.8(.00<r<1.00)$ and $p=0.003(p<0.05)$ in which shows that there is a significant effect on anxiety before and after therapy was given, and there variabilities or effects produced by the therapy. Based on this research shows that the repentance and seeking forgiveness therapy effective in lowering the anxiety level for Undergraduate students.
\end{abstract}

Keywords: repentance and seeking for forgiveness therapy, taubat dan istighfar, anxiety, undergraduate student

\begin{abstract}
ABSTRAK : Penelitian ini bertujuan untuk melihat pengaruh terapi taubat dan istighfar terhadap kecemasan. Subjek penelitian merupakan mahasiswa S1 Psikologi. Penelitian yang dilakukan berupa kuasi eksperimen, menggunakan analisa prates, paskates dan tindak lanjut. Sebelum dilakukan terapi, subjek diberikan skala kecemasan menggunakan Beck Anxiety Inventory (BAI), di mana subjek dengan kategori kecemasan tinggi dan sedang yang kemudian dijadikan subjek penelitian. Data hasil penelitian dianalisis menggunakan metode T-test untuk mengukur signifikansi dan effect size pada variabel yang ada. Berdasarkan data hasil penelitian diperoleh $\mathrm{r}=0,8(.00<\mathrm{r}<1.00)$ dan $\mathrm{p}=0,003(\mathrm{p}<0,05)$. Hal ini menunjukkan bahwa ada pengaruh yang signifikan terhadap kecemasan sebelum dan sesudah diberikan terapi taubat dan istighfar, serta ada variabilitas atau efek yang besar yang dihasilkan oleh terapi taubat dan istighfar terhadap kecemasan. Berdasarkan penelitian ini dapat disimpulkan bahwa terapi taubat dan istighfar memiliki pengaruh dalam menurunkan tingkat kecemasan pada mahasiswa.
\end{abstract}

Kata kunci: terapi taubat dan istighfar, kecemasan, mahasiswa

\footnotetext{
${ }^{1}$ Korespodensi mengenai artikel ini dapat melalui: sumedi.nugraha@uii.ac.id
} 
Gangguan kecemasan dan depresi menimpa sekitar 1.740 .000 orang (11.6\%) di Indonesia, dengan asumsi bahwa ada sekitar 150 juta penduduk dewasa (Kementerian Kesehatan Republik Indonesia, 2009). Menurut American Psychological Association (2010), meski gangguan kecemasan dapat mulai terjadi kapan saja, namun gangguan kecemasan biasanya pertama kali muncul pada masa remaja atau masa dewasa awal.

Ada banyak penelitian, seperti yang dilakukan oleh Rawson, dkk (1994), Misra dan McKean (2000) yang masing-masing menunjukkan bahwa kecemasan banyak dialami oleh mahasiswa yang umumnya berada pada rentang usia dewasa awal. Penelitian mereka melihat hubungan antara kecemasan dengan depresi, gangguan kesehatan, stres yang berhubungan dengan akademik, manajemen waktu, dan kepuasan pemanfaatan waktu luang. Di Indonesia ada 613.665 orang yang berstatus sebagai mahasiswa (Badan Pusat Statistik, 2014). Kecemasan pada level universitas, menurut hasil dari penelitian Hasianna, dkk (2014), Kristianto, dkk (2013), Syarifah (2013), dan Mu'arif (2005), berkisar antara 25,29\% hingga $50,30 \%$ pada derajat antara ringan hingga sedang yang tersebar di berbagai fakultas.

Hasil wawancara yang dilakukan kepada mahasiswa S1 Prodi Psikologi Universitas Islam Indonesia, menunjukkan ada berbagai macam hal yang dirasa merupakan sumber permasalahan yang menyebabkan mahasiswa merasa cemas. Masalah kecemasan menjadi penting untuk diteliti karena kecemasan dapat menghambat produktivitas seseorang. Apabila kecemasan ini tidak ditangani dengan baik maka akan berlanjut menjadi depresi.

Kecemasan merupakan emosi yang bersumber dari reaksi normal terhadap situasi yang tidak menentu dan dapat menyebabkan stres. Sebenarnya kecemasan merupakan reaksi wajar dari tubuh untuk memberitahukan agar tetap siaga dan menjaga diri (ADAA, 2016; APA, 2016). Reaksi yang wajar ini dapat berkembang menjadi gangguan dan menjadi hal yang penting untuk diperhatikan ketika kecemasan sudah di luar kemampuan individu untuk menguasainya yang berakibat menjadi depresi.

Biasanya orang yang mengalami depresi akan mencari jalan keluar melalui cara yang tidak tepat misalnya, dengan mengkonsumsi obat dan zat kimia terlarang (APA, 2010; Kementerian Kesehatan Republik Indonesia, 2009; Murray, 2016; NAMI, 2012). Oleh sebab itu, kecemasan sebagai sumber permasalahan perlu diminimalisir. Kecemasan berubah menjadi hal yang perlu dikhawatirkan ketika kecemasan yang timbul sebagai reaksi normal tubuh terhadap situasi tertentu berubah menjadi kecemasan terhadap halhal yang terjadi sehari-hari, menetap, tidak realistis, dan berlebihan.

Individu yang menderita kecemasan biasanya mengantisipasi akan terjadinya bencana, atau sangat prihatin terhadap masalah keuangan, kesehatan, keluarga, pekerjaan, pendidikan, dan masalah yang lainnya (wulandari \& Nashori, 2014). Terkadang kecemasan timbul hanya karena disebabkan oleh pikiran mengenai bagaimana menghadapi hari ini. Individu tidak tahu bagaimana caranya menghentikan dan sudah berada di luar batas kendalinya, meski individu biasanya menyadari bahwa kecemasan mereka lebih intens dibandingkan dengan situasi atau kenyataan yang mereka hadapi (ADAA, 2016). Dari penjelasan tersebut terlihat bahwa kecemasan perlu dikurangi atau dikendalikan.

Berkaitan dengan pengurangan, pengendalian maupun pencegahan 
kecemasan, dapat dilakukan berbagai macam cara. Salah satunya adalah dengan menggunakan Psikoterapi. Psikoterapi sendiri memiliki banyak metode, antara lain, Psikoterapi Humanistik, Psychodynamic Psychotherapy, Terapi Perilaku, dan masih banyak lagi psikoterapi yang lain, hingga yang dianggap paling baik untuk mengatasi kecemasan yaitu, CBT (Cognitive-Behavioral Therapy). Meski demikian, ada beberapa kelemahan dari CBT. Efektivitas terapi ini sangat tergantung kepada modifikasi perlakuan yang didasari pada perbedaan individual, seperti latar belakang pendidikan, keadaan ekonomi, kemampuan kognitif, hingga kondisi fisik individu, seperti pada mereka yang memiliki kerusakan sensori, begitu pula dengan motivasi untuk mempelajari dan melakukan hal yang baru serta kedisiplinan dalam menjalankan program yang telah direncanakan dalam jangka waktu yang lama (Larkin, 2008; Stanley, dkk, 2004). Untuk itu diperlukan metode terapi lain yang mampu mengatasi masalah kecemasan tanpa terkendala oleh hal-hal yang telah disebutkan sebelumnya.

Penelitian-penelitian yang dilakukan di Barat tersebut juga menunjukkan bahwa metode terapi yang diberikan hanya mengarah kepada perilaku dan pikiran manusia. Di dalam Islam, selain penyakit tidak hanya berkaitan dengan pikiran dan perilaku manusia, tetapi berkaitan juga dengan hati. Apa yang diyakini oleh hati tidak lepas dari apa yang dipikirkan oleh akal. Dengan menggunakan akal seseorang dapat berpikir dan dari proses berpikir akan timbul kepercayaan yang diwujudkan dalam perilaku. Perilaku sendiri menurut ar-Râzî dalam Arroisi (2013) ada tiga macam, yaitu tindakan hati, tindakan lisan, dan tindakan seluruh anggota badan.

Tindakan hati adalah pola pikir, keyakinan, dan kepercayaan, tindakan lisan adalah mengingat dan menyaksikan Allah, sementara tindakan anggota badan adalah taat dan ibadah kepada-Nya. Agar perilaku sejalan dengan pikiran, maka sebaiknya seseorang terlepas dari penyakit hati terlebih dahulu. Ada beberapa tanda yang menunjukkan bahwa seseorang terkena penyakit hati seperti, lebih mencintai yang lain selain Allah, berlebihan, kehilangan ketenteraman dan ketenangan batin, memiliki hati yang keras, kehilangan kekhusyukan dalam ibadah, malas beribadah atau beramal, dan senang melakukan dosa (Al-Ghazali, 1993).

Kehilangan ketenteraman dan ketenangan batin juga merupakan hal yang menunjukkan adanya kecemasan pada diri seseorang, karena seperti yang telah dikemukakan di atas, kecemasan membuat seseorang merasa selalu siaga dan mengantisipasi apa yang akan terjadi. Maka dibutuhkan terapi yang selain mampu mengurangi kecemasan yang merupakan penyakit hati, tetapi tidak terhalang oleh kendala dalam perbedaan individual dan ketidaknyamanan dalam mempelajari hal maupun kebiasaan yang baru. Terapi lain yang dapat memenuhi semua kriteria tersebut adalah terapi religiusitas atau spiritualitas karena sebagian besar terapi tersebut dalam penerapannya tidak terhambat oleh kendala seperti latar belakang pendidikan, keadaan ekonomi, kemampuan kognitif, dan kondisi fisik individu (Wachholtz dan Sambamoorthi, 2011).

Penggunaan terapi religius atau spiritual dianggap mampu mengatasi kecemasan (Koszycki, 2010). Terapi religius dan spiritual pun memiliki banyak cara, salah satunya adalah dengan menggunakan metode taubat dan istighfar. Metode taubat dan istighfar dipilih karena pada penelitian sebelumnya telah terbukti metode tersebut dapat mengurangi kecemasan (Uyun, 2016), dan meminta pengampunan (taubat/ muataba/atab) merupakan salah satu 
bentuk positif dari religious coping (Wachholtz dan Sambamoorthi, 2011; Keshavarzi, dan Haque, 2013).

\section{METODE PENELITIAN}

\section{Rancangan penelitian}

Penelitian ini merupakan penelitian eksprimen dengan menggunakan model rancangan pra dan pascates. Eksperimen yang dilakukan bertujuan untuk mengetahui efek yang ditimbulkan perlakuan yang diberikan. Desain penelitian menggunakan quasi-experimental dengan desain prates, paskates dan tindak lanjut atau follow-up. Dalam desain ini efek perlakuan dapat dilihat dengan membandingkan hasil yang diperoleh dari variabel dependen pada kelompok eksperimen setelah diberikan perlakuan dengan sebelum diberikan perlakuan (Azwar, 2003). Dalam penelitian ini tidak ada pembanding (kelompok kontrol)

Tabel 1. Rancangan Penelitian

\begin{tabular}{ccccc}
\hline Kelompok & Prates & Perlakuan & Paskates & Tindak Lanjut \\
Eksperimen & $\mathrm{O}_{1}$ & $\mathrm{X}$ & $\mathrm{O}_{2}$ & $\mathrm{O}_{3}$ \\
\hline
\end{tabular}

Keterangan:

$\mathrm{O}_{1} \quad$ : Prates

$\mathrm{O}_{2} \quad$ : Paska tes

$\mathrm{O}_{3} \quad$ : Tindak Lanjut

$\mathrm{X}$ : Perlakuan yang diberikan

\section{Subjek Penelitian}

Subjek dalam penelitian ini adalah mahasiswa S1 Prodi Psikologi Universitas Islam Indonesia dengan tingkat kecemasan sedang hingga tinggi yang dipilih menggunakan alat ukur kecemasan BAI (Beck Anxiety Inventory). Mahasiswa dengan hasil kecemasan tinggi sebanyak 28 orang, mahasiswa dengan tingkat kecemasan sedang sebanyak 68 orang. Dari keseluruhan 22 orang yang ditawarkan untuk mengikuti pelatihan, sebanyak sembilan orang yang sanggup dan bersedia mengikuti seluruh pelaksaan penelitian

\section{Metode Pengumpulan Data}

Metode pengumpulan data yang digunakan dalam penelitian ini menggunakan skala kecemasan dan lembar kerja yang merupakan catatan harian untuk memonitor serta mengetahui dampak dari pelaksanaan taubat dan istighfar yang dilakukan.

Skala kecemasan yang digunakan adalah milik Beck yaitu Beck Anxiety Inventory (BAI). Skala ini terdiri atas 21 aitem self-report inventory dalam bentuk pilihan ganda yang mengukur seberapa parah kecemasan yang dirasakan oleh remaja dan orang dewasa dengan jarak usia mulai dari 12 hingga 80 tahun (Grant, 2015). Setiap aitem yang ada di BAI merupakan gambaran sederhana dari aspek-aspek kecemasan. Responden diminta untuk menentukan pilihan mengenai apa yang terjadi terhadap dirinya selama seminggu terakhir. Individu diminta memilih salah satu dari empat pilihan jawaban yang sesuai dengan yang dirasakan (Beck, dkk, 1988). Ada empat pilihan yang terdiri dari tidak pernah $=0$, hampir tidak pernah $=1$, kadang-kadang $=2$, sering $=3$. Hasil yang didapat berkisar antara 0 hingga 63 , dengan kategori penilaian $0-7=$ sangat 
rendah, 8-15 = rendah, $16-25$ = sedang, $26-$ $63=$ tinggi .

\section{Intervensi}

Perlakuan yang diberikan dalam penelitian ini berupa terapi taubat dan istighfar yang telah dikembangkan oleh Uyun (2016). Intervensi diberikan kepada partisipan selama dua hari pertemuan dengan perkiraan waktu tiap materi adalah 15-90 menit untuk setiap sesinya. Pertemuan pertama terdiri atas tiga sesi, yaitu mengenai taubat dan istighfar, identifikasi permasalahan yang menyebabkan kecemasan pada dirinya, dan pemberian tugas yang dilakukan selama seminggu setelah pertemuan pertama. Selain itu peserta juga diminta untuk membuat catatan harian yang berisi hal-hal yang berkaitan dengan taubat dan Istighfar yang telah dilakukan.

Pada pertemuan kedua, peserta diminta untuk merefleksikan perasaan dan dampak dari taubat dan Istighfar yang telah dilakukan selama seminggu. Mereka diminta untuk menceritakan perasaan, pengalaman dan bagaimana pelaksanaan tugas rumah yang sudah diberikan sebelumnya. Peserta juga diminta untuk mengisi skala kecemasan setelah melakukan tugas rumah yang berupa catatan harian mengenai taubat dan istighfar yang telah dilakukan serta pengalaman apa saja yang dirasakan dan dialami selama melakukan taubat dan istighfar.

\section{Metode analisis data}

Analisis data yang digunakan untuk menguji hipotesis penelitian ini adalah dengan menggunakan uji perbedaan ratarata skor kecemasan antara skor sebelum diberikan terapi taubat dan istighfar dengan skor setelah diberikan terapi. Uji perbedaan rata-rata skor kecemasan juga dilakukan antara skor sebelum intervensi dan skor tindak lanjut. Analisis statistik yang digunakan adalah uji beda paired sample $t$ test.

\section{HASIL PENELITIAN}

Berdasarkan hasil penelitian yang dilakukan terhadap sembilan orang subjek didapat bahwa ada perubahan pada hampir semua subjek saat prates dan paskates, yang dapat dilihat pada tabel 2, di mana semua subjek mengalami penurunan skor kecemasan, kecuali pada subjek NS dan GN yang tetap pada skor yang sama. Pada subjek yang mengalami penurunan kecemasan pada saat paskates, selisih skor berkisar mulai dari 7 hingga 16 poin. Sedangkan selisih skor antara prates dan tindak lanjut terdapat beberapa perbedaan, di mana terdapat tiga subjek yaitu MFM, FDR, dan RAP yang mengalami peningkatan selisih skor, lima orang subjek mengalami penurunan selisih skor dan satu orang subjek yang tidak mengalami perbedaan skor.

Tabel 2. Deskripsi Statistik Penelitian

\begin{tabular}{cccc}
\hline & $\begin{array}{r}\text { Kecemasan } \\
\text { Paskates }\end{array}$ & $\begin{array}{c}\text { Kecemasan } \\
\text { TindakLanjut }\end{array}$ & Kecemasan_ Prates \\
\hline $\mathrm{N}$ & 9 & 9 & 9 \\
Minimum & 31 & 19 & 23 \\
Maksimum & 46 & 46 & 49 \\
Mean & 39.11 & 31.44 & 34.89 \\
Std. Deviation & 4.99 & 7.33 & 8.36 \\
\hline
\end{tabular}


Analisis data yang digunakan untuk menguji hipotesis dari penelitian ini adalah dengan menggunakan uji statistik T-test.
Hasil tersebut dapat dilihat pada tabel berikut.

Tabel 3. Hasil Uji Hipotesis

Paired Samples Test

\begin{tabular}{|c|c|c|c|c|c|c|c|c|c|}
\hline & & \multicolumn{5}{|c|}{ Paired Differences } & \multirow[t]{2}{*}{$\mathrm{t}$} & \multirow[t]{2}{*}{ df } & \multirow{2}{*}{$\begin{array}{l}\text { Sig. (2- } \\
\text { tailed) }\end{array}$} \\
\hline & & Mean & $\begin{array}{c}\text { Std. } \\
\text { Deviation }\end{array}$ & $\begin{array}{l}\text { Std. } \\
\text { Error } \\
\text { Mean }\end{array}$ & $\begin{array}{r}95 \% \text { Col } \\
\text { Interva } \\
\text { Diffel }\end{array}$ & $\begin{array}{l}\text { fidence } \\
\text { of the } \\
\text { ence }\end{array}$ & & & \\
\hline & & & & & Lower & Upper & & & \\
\hline Pair 1 & $\begin{array}{l}\text { Kecemasan_Prates - } \\
\text { Kecemasan_Paskates } \\
\text { Kecemasan_Prates - }\end{array}$ & 7.667 & 5.500 & 1.833 & 3.439 & 11.894 & 4.182 & 8 & .003 \\
\hline Pair 2 & $\begin{array}{l}\text { Kecemasan_Tindak } \\
\text { lanjut }\end{array}$ & 4.222 & 8.105 & 2.702 & -2.008 & 10.452 & 1.563 & 8 & .157 \\
\hline
\end{tabular}

Dari hasil perhitungan menunjukkan bahwa adanya efek dari variabel independen terhadap variabel dependen sebesar 0.8. Hasil uji beda menunjukkan ada perbedaan yang signifikan antara skor kecemasan pada mahasiswa sebelum dan setelah diberikan perlakuan dengan nilai $\mathrm{p}=0,003$.

\section{PEMBAHASAN}

Penelitian ini dilakukan untuk mengetahui pengaruh taubat dan istighfar terhadap kecemasan. Hasil penelitian menunjukkan bahwa ada perbedaan yang signifikan antara skor kecemasan pada mahasiswa sebelum dan setelah diberikan perlakuan, dilihat dari data yang diperoleh menggunakan uji statistik t-test di mana $\mathrm{p}=$ 0,003 . Nilai tersebut menunjukkan bahwa ada perubahan skor kecemasan sebelum dan setelah diberikan perlakuan. Melalui penjelasan di atas dapat dikatakan bahwa terapi taubat dan istighfar berpengaruh terhadap penurunan tingkat kecemasan mahasiswa S1 Psikologi Fakultas Psikologi dan Ilmu Sosial Budaya, Universitas Islam Indonesia. Hal ini juga berarti bahwa hipotesis yang diajukan dalam penelitian ini diterima, bahwa mahasiswa yang diberikan terapi taubat dan istighfar akan mengalami penurunan tingkat kecemasan, Hasil penelitian ini juga sesuai dengan hasil penelitian yang dilakukan oleh Uyun (2016) bahwa terapi istighfar dan taubat terbukti dapat menurunkan kecemasan dan depresi.

Terdapat beberapa hal yang memungkinkan adanya penurunan kecemasan setelah dilakukannya terapi istighfar dan taubat. Dilihat dari hasil pelaksanaan selama dilakukan terapi istighfar dan taubat berdasarkan hasil evaluasi pelatihan dan evaluasi trainer. Pada hasil evaluasi trainer, satu orang menilai sangat baik untuk keseluruhan kategori, lima orang mengatakan baik dan tiga orang mengatakan cukup. Untuk hasil evaluasi penelitian beberapa peserta menyatakan bahwa mereka menjadi lebih mengerti arti penting istighfar, lebih mampu mengidentifikasi masalah yang dihadapi dan menanganinya menggunakan istighfar. Adanya tugas rumah yang diberikan juga nampaknya membantu subjek penelitian 
sebagai pemicu semangat untuk melakukan taubat dan istighfar, terutama istighfar.

Pada pelaksanaannya, terapi istighfar dan taubat ini dilakukan dalam dua kali pertemuan, berbeda dengan apa yang direncanakan pada modul, yaitu dilaksanakan dalam tiga kali pertemuan. Hal ini disebabkan adanya kendala waktu pada pemberi terapi. Namun dalam pelaksanaannya, semua sesi diberikan sesuai dengan apa yang ditertera pada modul yang ada.

Pada hari pertama dilakukan sesi pertama, kedua dan ketiga. Pemberi materi merupakan dosen Prodi Psikologi yang memiliki pengalaman mengisi materi yang sesuai dengan terapi yang akan diberikan. Pada sesi pertama diberikan penjelasan mengenai istighfar dan taubat, dasar-dasar, pilar, dan waktu yang tepat untuk melakukan taubat. Sesi kedua berupa identifikasi masalah, di mana peserta diberikan kesempatan untuk mengidentifikasi permasalahan yang dihadapi, yang merupakan penyebab dari kecemasan yang dirasakan dan dialami. Di sesi ketiga, diberikan penjelasan mengenai tugas yang akan dilakukan oleh peserta, di mana peserta diminta untuk menuliskan pengalamannya selama melakukan istighfar dan taubat.

Pada hari kedua, atau seminggu setelah diberikannya tugas rumah, dilakukan sesi keempat, yaitu refleksi, yang merupakan sesi terakhir dari seluruh rangkaian penelitian. Sesi ini difasilitasi oleh psikolog yang berbeda dengan pengisi terapi pada hari pertama, hal ini dikarenakan adanya kendala waktu. Pada sesi ini, sebagian besar dari peserta mengatakan bahwa di awal minggu dilakukannya tugas rumah mereka masih belum merasakan adanya perubahan namun kemudian mereka mulai merasakan dampak positif dari melakukan istighfar dan taubat, sebagian lagi mengatakan bahwa mereka merasakan adanya perbedaan dari awal mereka melakukan istighfar dan taubat. Sebagian besar dari mereka mengatakan bahwa masih merasa kesulitan untuk melakukan taubat dengan melakukan shalat taubat.

\section{SIMPULAN DAN SARAN}

\section{Simpulan}

Berdasarkan hasil analisis data yang didapat setelah dilakukan terapi dan tugas rumah individu maka dapat disimpulkan bahwa terapi taubat dan istighfar memberikan pengaruh terhadap penurunan tingkat kecemasan pada mahasiswa S1 Prodi Psikologi, Fakultas Psikologi dan Ilmu Budaya Dasar Universitas Islam Indonesia. Terdapat perbedaan tingkat kecemasan pada subjek saat dilakukan prates, pascates dan pada tindak lanjut. Berdasarkan analisis kualitatif juga didapatkan adanya perbedaan pengalaman dan perasaan pada sebagian besar subjek, di mana mereka menyatakan bahwa merasakan adanya perubahan yang terjadi di sekitar mereka dan cara mereka memandang suatu masalah.

\section{Saran}

$$
\text { Peneliti selanjutnya dapat }
$$
melakukan penelitian ulang dengan menggunakan subjek yang lebih bervariasi dalam hal seperti latar belakang pendidikan maupun jenis kelamin serta dengan jumlah yang responden yang lebih besar. Pengembangan modul penelitian disarankan dilakukan dengan merujuk kepada permasalahan yang akan diteliti. Berkaitan dengan rancangan penelitian disarankan agar diikut sertakan kelompok pembanding (kelompok kontrol). 


\section{DAFTAR PUSTAKA}

Al-Ghazali, A. (1993). Ihya Ulum-Id-Din: Revival of Religious Learning. Penerjemah azl-Ul-Karim. Karachi: Darul-Ishaat

Al-Ghazali, A. (2013). Ihya' Ulumiddin: Menghidupkan Kembali Ilmu Agama (Bagian 7: Pintu Taubat) (diterjemahkan dari kitab Ihya' Ulumiddin). Penerjemah: Ibnu Ibrahim Ba'adillah. Jakarta: Republika

American Psychological Association. (2010). FYI: Understanding Anxiety Disorder and Effective Treatment. Diunduh pada tanggal 23 Juni 2016 dari http://www.apa.org/ monitor/jun06/emerging.aspx

Azwar, S. (2003). Metode Penelitian. Yogyakarta: Pustaka Pelajar

Beck, A.T., Brown, G., Epstein, N. Steer, R.A. (1988). An Inventory for Measuring Clinical Anxiety: Psychometric Properties. Journal of Consulting and Clinical Psychology, Vol. 56(3), 893897.

Hasianna, S.T., Surawijaya, A.K., \& Maulana, T. A. (2014). Gambaran Tingkat Kecemasan pada Mahasiswa Semester Satu di Fakultas Kedokteran Universitas Kristen Maranatha Tahun 2014. Diunduh pada tanggal 23 Juni 2016. http://repository.maranatha. edu/12445/10/1010167 Journal.pdf

Kementerian Kesehatan Republik Indonesia. (2009). Kesehatan Jiwa sebagai Prioritas Global. Diunduh pada tanggal 23 Juni 2016 dari http://www.depkes.go.id/article /view/394/kesehatan-jiwa-sebagaiprioritas- global.html
Keshavarzi, H., \& Haque, A. (2013). Outlining a Psychotherapy Model for Enhancing Muslim Mental Health Within an Islamic Context. The International Journal for the Psychology of Religion, 23(3), 230-249

Kristianto, H., Wihastuti, T.A., \& Al-Maris, R. (2013). Perbedaan Tingkat Kecemasan Mahasiswa dalam Menyelesaikan Tugas dengan Pembagian Kelompok Berdasarkan Metode Friendship Group dan Random Group di Fakultas Kedokteran Universitas Brawijaya. Jurnal Ilmu Keperawatan, Vol.1(2),113-118

Koszycki, D., Raab, K., Aldosary, F., \& Bradwejn, J. (2010). A Multifaith Spiritually Based Intervention for Generalized Anxiety Disorder: A Pilot Randomized Trial. Journal of Clinical Psychology, Vol. 66(4), 430-441 (2010)

Larkin, K.T. (2008). Psychotherapy. Dalam Vanin, J.R., \& Helsley, J.D. (Ed.), Anxiety Disorders:A Pocket Guide for Primary Care.New Jersey:Humana Press.

Murray, W. (2016). No More Constant Fear. Diunduh tanggal 23 Juni 2016 dari http//www.adaa.org/living-withanxiety/personal-stories/no-moreconstant-fear

Rawson, H. E., Bloomer, K., \& Kendall, A. (1994). Stress, Anxiety, Depression, and Physical Illness in College Students. The Journal of Genetic Psychology,155(3), 321-30. Retrieved from_http://search.proquest.com/ docview/228521544?accountid=137 $\underline{71}$ 
Stanley, M. A., Diefenbach, G. J., \& Hopko, D.R. (2004). Cognitive Behavioral Treatment for Older Adults With Generalized Anxiety Disorder: A Therapist Manual for Primary Care Settings. Behavior Modification, 28 (1), 73-117.

Uyun, Q. (2016). Pengembangan Terapi Taubat dan Istighfar sebagai Intervensi terhadap Kesehatan Jiwa: Studi Pendahuluan. Laporan Penelitian. Tidak Dipublikasikan. Yogyakarta: UII.

Vanin, J.R., \& Helsley, J.D. (2008). Anxiety Disorders: A Pocket Guide for Primary Care. New Jersey: Humana Press
Wachholtz, A., \& Sambamoorthi, U. (2011). National Trends in Prayer Use as a Coping Mechanism for Health Concerns: Changes From 2002 to 2007. Psychology of Religion and Spirituality, Vol. 3 (2), 67-77

Wulandari, E., \& Nashori, H.F. (2014). Pengaruh Terapi Zikir terhadap Kesejahteraan Psikologis Pada Lansia. Jurnal Intervensi Psikologi, 6 (2), 235-250. 
Dian Nugrahati, Qurotul Uyun \& Sumedi P Nugraha 